\title{
Optimizing Material Selection using a Hybridized Multi-attribute Decision Making Model
}

\author{
ESLAM MOHAMMED ABDELKADER \\ Structural Engineering Department, Faculty of Engineering, \\ Cairo University, Giza, EGYPT \\ ABOBAKR AL-SAKKAF \\ Dept. of Building, Civil, and Environmental Engineering \\ Concordia University, Montréal, CANADA \\ Dept. of Architecture \& Environmental Planning, College of Engineering \& Petroleum, \\ Hadhramout University, Mukalla, YEMEN \\ GHASAN ALFALAH \\ Dept. of Architecture and Building Science, College of Architecture and Planning \\ King Saud University, Riyadh, SAUDI ARABIA
}

\begin{abstract}
Material selection is a very entangled and decisive stage in the design and development of products. There are large numbers of on hand and newly developed materials available in the market. In addition, inability to select the correct materials adversely affects the reputation and profitability of the company. Thus, designers need to study and trace the performance of available materials with appropriate functionalities. Thus, this research aims at establishing an efficient and systematic platform for the optimum selection of materials while accommodating the designated conflicting performance requirements. The developed model encompasses designing a hybrid decision support system in an attempt to circumvent the shortcomings of single multi-criteria decision making-based (MCDM) models. First, the objective relative importance weights of attributes are interpreted capitalizing on Shannon entropy algorithm. Then, an integrated model that encompasses the utilization of six different types of multi-criteria decision making algorithms is designed to create a reliable selection of material alternatives. The utilized MCDM algorithms comprise weighted product method (WPM), simple additive weighting (SAW), additive ratio assessment (ARAS), new combinative distance-based assessment (CODAS), complex proportional assessment (COPRAS) and technique for order of preference by similarity to ideal solution (TOPSIS). Afterwards, COPELAND algorithm is exploited to generate a consensus and distinct ranking of material alternatives. Eventually, Spearman's rank correlation analysis is used to evaluate the rankings obtained from the MCDM algorithms. Five numerical examples in diverse fields of material selection are tackled to examine the features and efficiency of the developed integrated model. Results illustrated that the developed model was able to solve the five material selection problems efficiently. On the other hand, no individual MCDM algorithm was able to solve all the assigned material selection problems. For instance, CODAS and TOPSIS only succeeded in solving one and two material selection problems, respectively. It was also inferred that notable differences and perturbations are encountered between the rankings of MCDM algorithms in the first, third, fourth and fifth numerical examples, which necessitates the implementation of COPELAND algorithm. It was also revealed that the highest correlation lied between COPRAS and WPM with an average Spearman's rank correlation coefficient of 92.67\%. On the other hand, the correlation between TOPSIS and CODAS attained the lowest rank with an average Spearman's rank correlation coefficient of $18.95 \%$. Results also demonstrated that COPRAS accomplished the highest Spearman's rank correlation coefficient with 59.54\%. Hence, it is the most efficient MCDM algorithm among the five algorithms which can serve as a reference for solving material selection problems. It can be also deduced that CODAS and TOPSIS are not advised to be implemented in solving similar material selection problems.
\end{abstract}

Key-Words: - Material selection; multi-criteria decision making; Shannon entropy; WPM; COPRAS; COPELAND; Spearman's rank correlation

Received: January 6, 2021. Revised: July 11, 2021. Accepted: July 23, 2021. Published: August 3, 2021. 


\section{Introduction}

Selection of materials plays a major role during the design and manufacturing processes. There are over 100,000 materials in the world. Each one has its own distinctive properties alongside its pros and cons. In addition, there are several conflicting criteria that need to be taken into consideration for the sake of proper material selection such as chemical properties, physical properties, mechanical properties, financial requirements aesthetic value, environmental impact, etc. Selection of materials plays a key role in the success and failure of the organization. In this regard, failure to select the correct material can undermine the reputation, profitability and productivity of the company $[1,2]$. Complexity of Selection of materials requires formulating a multi-criteria decision making problem. In the past few decades, multi-criteria decision making has been one of the fast growing approaches employed to solve engineering problems. Multi-criteria decision making process encompasses the following: 1) defining relevant design attributes and alternatives, 2) linking numerical measures to the relative importance of attributes and performance scores of alternatives and 3 ) process the performance scores and weights to evaluate the ranking of alternatives. There are various multi-criteria decision making such as analytical hierarchy process, weighted sum model (WSM), elimination and choice translating reality (ELECTRE), preference ranking organization method for enrichment evolution (PROMETHEE), operational competitiveness ratings analysis (OCRA), etc. Recently, multi-criteria decision making under interval neutrosophic setting is introduced to deal with inconsistencies and incomplete information [3].

In view of the above, this research an integrated multi-criteria decision making model for optimizing material selection process in the light of presence of wide range of available material alternative and conflicting performance criteria. Thus, the main objectives of the present research study lie in the following:

1. Develop a hybrid multi-criteria decision making model for sustainable material selection.

2. Study the level of consistencies between the employed MCDM algorithms.

3. Validate the developed integrated model through several case studies.

Several material selection models have been proposed which exploited the use of multi-criteria decision making. Singh et al. [4] proposed multicriteria decision making approach for the selection of the most suitable metal matrix composite. Several material alternatives were studied according to their melting point, cost, density, hardness and tensile strength. Fuzzy analytical hierarchy process was implemented to find the weights of judging attributes. Then, TOPSIS algorithm was used to identify the most suitable design material. Chatterjee et al. [5] studied the implementation of multi-criteria decision making for solving material selection problems of light weight automotive industries. In this context, several material alternatives were studied including low strength, high strength steel, cast aluminum, magnesium aluminum, advanced high strength steel, etc. The materials were appraised based on some attributes such as modulus of elasticity, yield strength, tensile strength, thermal performance, corrosion resistance, etc. Entropy algorithm was used to find the weights of attributes. The rankings of alternatives were then explored by the help of multi attributive ideal real comparative analysis (MAIRCA) algorithm.

Dhanaraj and Rathinasuriyan [6] introduced an approach that enables the selection of the material for energy weld process. The materials were compared according to welding quality, ease of automation, cost of welding, work safety level, environmental effects, energy requirements, etc. Analytical hierarchy process was used to find the weights of attributes and sort the material alternatives. Results demonstrated that welding quality is the most important attribute followed by cost of welding while initial preparation requirement is the least important attribute. Reddy et al. [7] introduced a quantitative approach for sustainable concrete assessment. Five concrete options were investigated, namely ordinary portland cement, Pozzolona Portland Cement Flyash based, Pozzolona Portland Cement Slag based, Metakaolin and composite cement. The best material alternative were identified including life cycle cost, split tensile, flexural strength, workability, compressive strength, etc. The prioritization of material alternatives was carried out using TOPSIS algorithm, whereas Pozzolona Portland Cement Flyash based concrete was found to be the most concrete option.

Demir [8] presented a knowledge-based system for the purpose of fine aggregate selection in concrete production. In the developed model, the fine aggregates were assessed based on set of attributes, namely methylene blue, compressive strength, water absorption by volume, ultrasonic pulse velocity, flexural strength, water absorption by volume, capillary coefficient, and modulus of dynamic elasticity. Five different five aggregates were studied, whereas TOPSIS algorithm was applied to 
find the best fine aggregate series. Zoghi et al. [9] introduced a model that aimed the selection of the most feasible materials of building components. Kano model was first used to identify and categorize of the most relevant design attributes. Thus, eight design criteria were considered which were: expected durability, space for equipment and maneuvering, parallel flexibility, reusable materials and components, etc. Fuzzy analytical hierarchy process was deployed to extract the weights of attributes. A final ranking of the material alternatives in five building components were defined based on fuzzy TOPSIS algorithm.

Patnaik et al. [10] presented a methodology for the sake of selecting of best polymer composite material in engineering applications. The selection process was performed according to specific wear rate, impact strength, flexural strength, tensile strength, density, etc. Analytical hierarchy process was used to obtain the weightage of attributes. Multiobjective optimization on the basis of ratio analysis (MOORA) algorithm was utilized to prioritize the compared material alternatives. Kiani et al. [11] introduced a model that enabled the selection of best repair material for concrete structures. The repair materials were compared using a set of criteria, namely shrinkage, net creep, bond strength, Poisson's ratio, tensile modulus and tensile strength. Five material alternatives were experimented which were acrylic mortar, sand mortar, polyester mortar, epoxy mortar and SBR modified. VIKOR algorithm was then used for sorting patch repair materials.

Falqi et al. [12] introduced multi-criteria decision making approach for sustainable assessment of siliceous concrete materials. The siliceous concrete materials were evaluated as per economic, social, technical and environmental requirements. The judging criteria encompassed lifelong maintenance cost, concrete production cost, energy conservation, concrete curing system, concrete compaction system, etc. Fuzzy TOPSIS algorithm was finally employed for the ranking of siliceous concrete materials. Results showed that nano-cement is the most sustainable material while recycled aggregate is the least sustainable one. Rashid et al. [13] proposed a model for the optimal selection of concrete mix design based on multi-criteria decision making. The mix designs were assessed based on some attributes such as raw materials, environmental impact, amount of water, cost of materials, amount of water to cement ratio, compressive strength. Analytical hierarchy process was then deployed for the optimized selection of concrete mix design.

\section{Proposed Model}

The ultimate objective of the present research study is to establish an integrated model that aims at selecting the most sustainable materials. The framework of the proposed model is presented in Figure 1. The first step is to define the main goal, design attributes and the available material alternatives. The next step is to obtain the relative importance weighting vector of the design attributes based on Shannon entropy algorithm. It is an objective weight interpretation algorithm that relies on the variations in the performance scores to find the attributes' weights. Shannon entropy is a widelyused algorithm that has been successfully employed in several engineering applications such as minimizing environmental emissions [14], optimal operation of dam reservoir [15], ranking renewable energy sources [16] and storm water management [17].

An accurate decision support system requires exploring and analyzing several different types of multi-criteria decision making algorithms [18, 19, 20]. In this regard, the proposed model studies the utilization of six different types of multi-criteria decision making algorithms for the sake of prioritizing material alternatives. The variable "NUM_MCDM" stands for total number of MCDM algorithms. The used algorithms encompass WPM, SAW, ARAS, CODAS, COPRAS and TOPSIS.. As a result of the implementation of several multicriteria decision making algorithms, different rankings of material alternatives are obtained [21, 22]. In this regard, the developed model exploits COPELAND algorithm to aggregate and converge the rankings of material alternatives into a final consensus ranking $[23,24]$. COPELAND algorithm proved its efficiency in dealing with wide range of diverse application such as minimization of seawater intrusion [25], prioritization of road maintenance plans [26], optimal service selection [27] and six sigma project selection [28]. The basic assumption of the developed model is that exact information about the performance scores of the design alternatives is available.

Five numerical examples in the field of material selection are extracted from the literature to validate the developed model and describe its capabilities. The variable "NUM_EX" denotes total number of case studies examined in the present research study. The case studies are chosen to cover wide range of applications in material selection, and to encompass different numbers of alternatives and design attributes in order to test the applicability and generalization of the developed model. The case 
studies are pertinent to the selection of construction materials, gear materials, energy efficient materials, tool holder materials and mechanical components' materials. Spearman's rank correlation coefficient is deployed to investigate the level of correlation between each pair of multi-criteria decision making algorithms.

\section{Model Development}

Herein, some of the techniques mentioned in the "Proposed Model" section are described in detail.

\subsection{Shannon Entropy}

Shannon entropy is an objective weight interpretation algorithm that is used to derive the weights of attributes based on the contrast and dispersion in the performance scores of the alternatives. In this context, higher contrast indicates higher importance of the alternative. On the other hand, lower dispersion indicates a less important design attribute. The steps of Shannon entropy algorithm are as follows [29, 14]:

The first step is to normalize the performance scores of the input decision matrix as follows

$\mathrm{n}_{\mathrm{ij}}=\frac{\mathrm{x}_{\mathrm{ij}}}{\sum_{\mathrm{i}=1}^{\mathrm{m}} \mathrm{x}_{\mathrm{ij}}} \quad(1 \leq \mathrm{i} \leq \mathrm{m}, 1 \leq \mathrm{j} \leq \mathrm{n})$

Where;

$\mathrm{x}_{\mathrm{ij}}$ is the performance index of the $\mathrm{i}-$ th alternative with respect to $j-$ th attribute. $P_{i j}$ is the normalized performane score of the $\mathrm{i}-$ th alternative with respect to $j-$ th attribute. $n$ and $m$ stand for numbers of attributes and alternatives, respectivley. After the normalization process, the next step is to compute the entropy value of each atrribute as shown in Equation (2).

$\mathrm{e}_{\mathrm{j}}=-\mathrm{k} \times \sum_{\mathrm{i}=1}^{\mathrm{m}} \mathrm{n}_{\mathrm{ij}} \times \ln \left(\mathrm{n}_{\mathrm{ij}}\right)(1 \leq \mathrm{i} \leq \mathrm{m}, 1 \leq \mathrm{j} \leq$ n)

Such that;

$\mathrm{k}=\frac{1}{\ln (\mathrm{m})}$

Where;

$e_{j}$ stands for the Entropy value of the $j-$ th design attribute.

The third step is to interpret the inherent contrast intensity for each design attribute as shown in Equation (4).

$\mathrm{d}_{\mathrm{j}}=1-\mathrm{e}_{\mathrm{j}}$
Where;

Higher value of $d_{j}$ indicates a more important criterion.

The final step is to calculate the objective weightage of each attribute using Equation (5).

$w_{j}=\frac{d_{j}}{\sum_{j=1}^{n} d_{j}}$

\subsection{SAW}

It is a widely-used algorithm that is capitalized on the linear utility function for the evaluation of alternatives. Its implementation steps are as follows [30, 31]:

The first step is the normalization process which depends on the type of criteria. The normalization process in the cases of benefit and cost criteria can be done using Equations (6) and (7), respectively.

$\mathrm{n}_{\mathrm{ij}}$

$=\frac{x_{i j}}{\max \left(x_{i j}\right)}$

$\mathrm{n}_{\mathrm{ij}}=\frac{\min \left(\mathrm{x}_{\mathrm{ij}}\right)}{\mathrm{x}_{\mathrm{ij}}}$

Where;

$\mathrm{n}_{\mathrm{ij}}$ is the normalized performance score of the the $\mathrm{i}-$ th alternative with respect to $\mathrm{j}-$ th attribute.

The overall score of each alternative can be computed through the summation of weighted normalized performance scores as shown in Equation (8).

$S_{i}=\sum_{j=1}^{n} w_{j} \times n_{i j}$

Where;

A higher value of $S_{i}$ indicates a better alternative. 


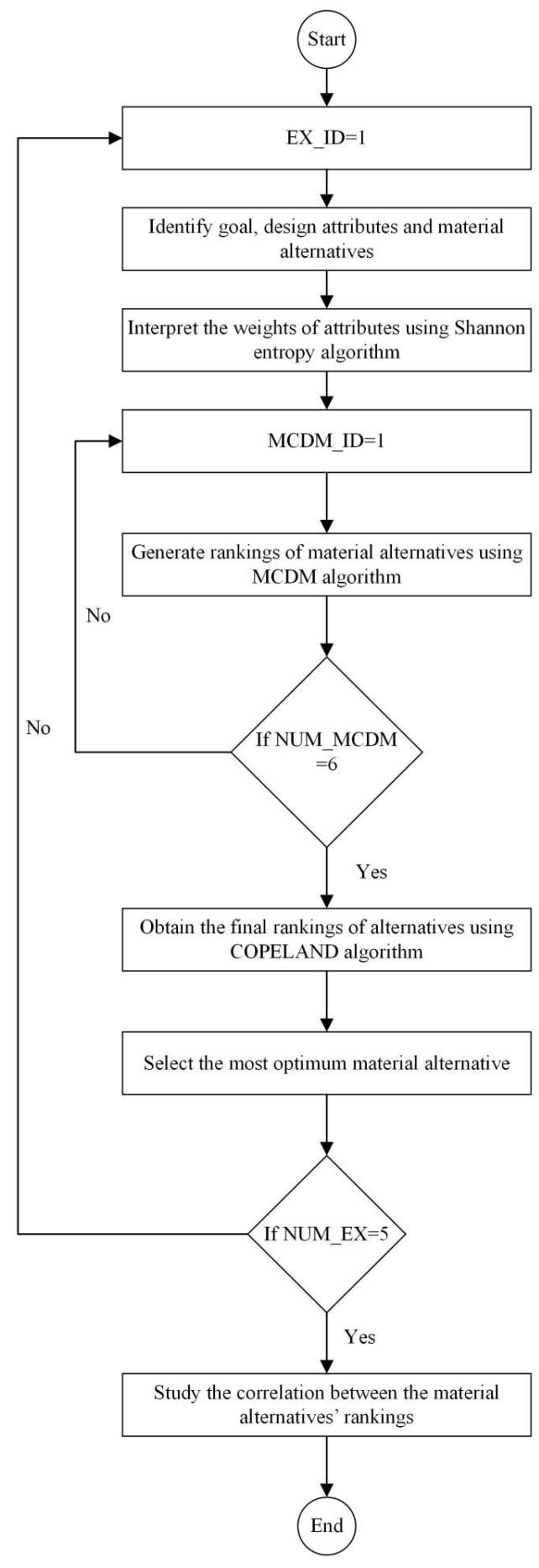

Fig.1: Flowchart of the developed material selection model.

\subsection{ARAS}

This algorithm involves the use of utility function to estimate the relative efficiency of alternatives. Its basic steps are reported in the following lines [32,33]:

The first is the normalization of the initial decision matrix, whereas the initial values are normalized based on the type of attribute. The normalization process of the performance indices in the beneficial and non-beneficial attributes is accomplished using Equations (9) and (10), respectively.

$r_{i j}=\frac{x_{i j}}{\sum_{i=1}^{m} x_{i j}}$

$r_{i j}=\frac{x^{\wedge}{ }_{i j}}{\sum_{i=1}^{m} x^{\wedge}{ }_{i j}}$

Such that;

$\mathrm{x}^{\wedge}{ }_{\mathrm{ij}}=\frac{1}{\mathrm{x}_{\mathrm{ij}}}$

The weighted normalized decision matrix can be expressed using Equation (12).

$v_{i j}=w_{j} \times n_{i j}$

The total function value (utility function) of each alternative is calculated according to Equation (13).

$S_{i}=\sum_{j=1}^{n} w_{j} \times v_{i j}$

The relative utility degree of each alternative can be expressed as follows.

$\mathrm{K}_{\mathrm{i}}=\frac{\mathrm{S}_{\mathrm{i}}}{\mathrm{S}_{0}}$

Where;

$\mathrm{S}_{0}$ refers to the optimum function value of the $\mathrm{i}-\mathrm{th}$ alternative. The obtained values of $\mathrm{K}_{\mathrm{i}}$ lie within the interval $[0,1]$. The best alternative is the one that has the highest value of $\mathrm{K}_{\mathrm{i}}$.

\subsection{CODAS}

CODAS algorithm utilizes two measures to determine the preference of the alternative which are: its Euclidean distance from the negative ideal solution and Taxicab distance from the negative ideal solution. Its computational steps are presented in the following lines $[34,35]$ :

The first step is the linear normalization process for the benefit and cost attributes as reported in Equations (15) and (16), respectively.

$\mathrm{n}_{\mathrm{ij}}$

$=\frac{x_{i j}}{\max \left(x_{i j}\right)}$

$\mathrm{n}_{\mathrm{ij}}=\frac{\min \left(\mathrm{x}_{\mathrm{ij}}\right)}{\mathrm{x}_{\mathrm{ij}}}$ 
The second step is to calculate the weighted normalized decision matrix as given by Equation (17).

$\mathrm{v}_{\mathrm{ij}}=\mathrm{w}_{\mathrm{j}} \times \mathrm{n}_{\mathrm{ij}}$

The third step is to identify the negative ideal solution with regards to each criterion as follows.

$n s_{j}=\min \left(v_{i j}\right)$

The next step is to calculate the Euclidean distance and Taxicab distance of each alternative from each negative ideal solutions as given by Equations (19) and (20), respectively.

$$
\begin{aligned}
& E_{i}=\sqrt{\sum_{j=1}^{n}\left(v_{i j}-n s_{j}\right)^{2}} \\
& T_{i}=\sum_{j=1}^{n}\left|v_{i j}-n s_{j}\right|
\end{aligned}
$$

The fifth step is to construct relative assessment matrix as shown in Equations (21) and (22).

$$
\begin{aligned}
& \mathrm{R}_{\mathrm{a}}=\left[\mathrm{h}_{\mathrm{ik}}\right]_{\mathrm{n} \times \mathrm{n}} \\
& \mathrm{h}_{\mathrm{ik}}=\left(\mathrm{E}_{\mathrm{i}}-\mathrm{E}_{\mathrm{k}}\right)+\Psi\left(\mathrm{E}_{\mathrm{i}}-\mathrm{E}_{\mathrm{k}}\right) \times\left(\mathrm{T}_{\mathrm{i}}-\mathrm{T}_{\mathrm{k}}\right)
\end{aligned}
$$

Where;

$\mathrm{k} \in\{1,2,3,4,6, \ldots \ldots \mathrm{n}\} . \Psi$ refers to a threshold function that identifies the equality of the Euclidean distances of two alternatives as given by Equation (23).

$\Psi(x)= \begin{cases}1 & \text { if }|x|>\tau \\ 0 & \text { if }|x|<\tau\end{cases}$

Where;

$\tau$ is a threshold parameter which is usually set as $0.02[36,37]$.

The final step is to compute the final assessment score for each alternative as shown in Equation (24).

$\mathrm{H}_{\mathrm{i}}=\sum_{\mathrm{k}=1}^{\mathrm{n}} \mathrm{h}_{\mathrm{ik}}$

Where;

The alternatives are sorted in a descending order according to the assessment score of $\mathrm{H}_{\mathrm{i}}$. In this context, a higher value of $\mathrm{H}_{\mathrm{i}}$ indicates a better option among the set of alternatives.

\subsection{COPELAND}

COPELAND is regarded as a modified version of BORDA count algorithm [38,39]. It is used to aggregate and consolidate the different rankings of the multi-criteria decision making algorithms. Assume "M" multi-criteria decision making algorithms. In COPELAND algorithm, each pair of alternatives is compared against each other with regards to the " $\mathrm{M}$ " studied multi-criteria decision making algorithm. The alternative that accomplishes a higher number of predominance attains a win and known as "Winner" and the other alternative is known as "Loser" [40]. In this context, number of predominance implies number of MCDM algorithms in which an alternative outranks the other. The alternatives are sorted stepping on a final score, which is generated by subtracting number of losses from number of wins as shown in Equation (25) [41]. When all pair-wise comparisons are finalized, the alternatives are sorted in a descending order, whereas the most optimum alternative is the one that accomplishes a higher final score. It is worth noting that alternatives with equal final score obtain an equal ranking.

$S C_{i}=\sum_{i=1}^{m} W_{i}-L_{i}$

Where;

$\mathrm{W}_{\mathrm{i}}$ and $\mathrm{L}_{\mathrm{i}}$ stand for number of wins and losses attained by each alternative, respectively. $\mathrm{SC}_{\mathrm{i}}$ denotes the final score of each alternative.

\section{Model Implementation}

In this section, five real case studies are adopted from the literature to examine the applicability of the developed model.

\subsection{Numerical Example (1)}

The first example is a material selection problem of construction projects that is extracted from Marzouk [42]. It considers five material alternatives and four attributes. In Table 1, the original data of the case study is recorded. The considered material alternatives are clear glass, tinted glass-single glazed, tinted glass-double glazed, reflective glass and glass plus $3 \mathrm{M}$ film. The judging attributes are initial cost, annual savings, aesthetics and ease of installation. The cost attribute is initial cost while 
the benefit attributes are annual saving, aesthetics and ease of installation. Table 2 shows the entropy value, inherent contrast intensity and weight of each design attribute. It can be observed that from Table 2 that ease of installation and aesthetics have nearly equal weight. In this regard, aesthetics and ease of installation have weighting value of $52.84 \%$ and $55.83 \%$, respectively.

Table 1. Original decision matrix of first numerical example adopted from Marzouk [42]

\begin{tabular}{ccccc}
\hline $\begin{array}{c}\text { Material } \\
\text { alternative }\end{array}$ & Initial cost & $\begin{array}{c}\text { Annual } \\
\text { savings }\end{array}$ & Aesthetics & $\begin{array}{c}\text { Ease of } \\
\text { installation }\end{array}$ \\
\hline clear glass & 60000 & 0 & 20 & 100 \\
\hline $\begin{array}{c}\text { Tinted glass-single } \\
\text { glazed }\end{array}$ & 75000 & 7600 & 40 & 70 \\
\hline $\begin{array}{c}\text { Tinted glass double } \\
\text { glazed }\end{array}$ & 100000 & 15200 & 40 & 70 \\
\hline Reflective glass & 750000 & 7600 & 70 & 70 \\
\hline Glass plus 3M film & 750000 & 11400 & 60 & \\
\hline
\end{tabular}

Table 2. Final weights of attributes of first numerical example

\begin{tabular}{ccccc}
\hline Index & $\begin{array}{c}\text { Initial } \\
\text { cost }\end{array}$ & $\begin{array}{c}\text { Annual } \\
\text { savings }\end{array}$ & Aesthetic & $\begin{array}{c}\text { Ease of } \\
\text { installation }\end{array}$ \\
\hline Entropy value & 0.484 & 0.614 & 0.053 & 0.776 \\
\hline $\begin{array}{c}\text { Inherent contrast } \\
\text { intensity }\end{array}$ & 0.516 & 0.386 & 0.265 & 0.224 \\
\hline Weight & $34.81 \%$ & $44.13 \%$ & $52.84 \%$ & $55.83 \%$ \\
\hline
\end{tabular}

Table 3. Full rankings of material alternatives in the first numerical example

\begin{tabular}{ccccccc}
\hline Material alternative & TOPSIS & SAW & COPRAS & WPM & ARAS & CODAS \\
\hline clear glass & 1 & 5 & 5 & 5 & 5 & 1 \\
\hline Tinted glass-single glazed & 2 & 3 & 2 & 1 & 2 & 5 \\
\hline Tinted glass-double glazed & 3 & 2 & 1 & 2 & 1 & 4 \\
\hline Reflective glass & 4 & 4 & 4 & 4 & 3 & 3 \\
\hline Glass plus 3M film & 5 & 1 & 3 & 3 & 4 & 2 \\
\hline
\end{tabular}

Table 3 shows the rankings of material alternatives based on the six multi-criteria decision making algorithms. Based on TOPSIS algorithm, clear glass is the most preferable alternative based on TOPSIS and CODAS. Tinted glass-single glazed is the best alternative based on WPM. It can be found also that tinted glass-double glazed is the optimum alternative according to COPRAS and ARAS. Glass plus $3 \mathrm{M}$ film is the best alternative with regards to
SAW. COPELAND algorithm is implemented to generate final rankings of the material alternatives as shown in Table 4. In Table 4, it can be noticed that tinted glass-double glazed has the highest net value based on the wins and losses. Hence, it accomplished the first ranking followed by tinted glass-single glazed while clear glass has the lowest ranking.

Table 4. Final rankings of material alternatives in the first numerical example

\begin{tabular}{ccccc}
\hline Material alternative & Loss & Win & Difference & Rank \\
\hline clear glass & 4 & 0 & -4 & 5 \\
\hline Tinted glass-single glazed & 1 & 3 & 2 & 2 \\
\hline Tinted glass-double glazed & 0 & 4 & 4 & 1 \\
\hline Reflective glass & 3 & 1 & -2 & 4 \\
\hline Glass plus 3M film & 2 & 2 & 0 & 3
\end{tabular}

\subsection{Numerical Example (2)}

The second numerical example is gear material selection problem that is borrowed from Milani et al. [43]. The input data matrix is reported in Table 5 . The second case study takes into consideration nine material options and five design criteria. The 
material options are cast iron, ductile iron, S.G iron, cast alloy steel, through hardened alloy steel, surface hardened alloy steel, carburised steel, nitrided steel and through hardened carbon steel. The design attributes are surface hardness, core hardness, surface fatigue limit, bending fatigue limit and ultimate tensile strength. In this context, the beneficial attribute involve surface hardness, surface fatigue limit, bending fatigue limit and ultimate tensile strength. The cost attribute is core hardness.

Table 5. Original decision matrix of second numerical example adopted from Milani et al. [43]

\begin{tabular}{|c|c|c|c|c|c|}
\hline Material alternative & $\begin{array}{c}\text { Surface } \\
\text { hardness }\end{array}$ & $\begin{array}{c}\text { Core } \\
\text { hardness }\end{array}$ & $\begin{array}{c}\text { Surface fatigue } \\
\text { limit }\end{array}$ & $\begin{array}{l}\text { Bending fatigue } \\
\text { limit }\end{array}$ & $\begin{array}{c}\text { Ultimate tensile } \\
\text { strength }\end{array}$ \\
\hline Cast iron & 200 & 200 & 330 & 100 & 380 \\
\hline Ductile iron & 220 & 220 & 460 & 360 & 880 \\
\hline S.G iron & 240 & 240 & 550 & 340 & 845 \\
\hline Cast alloy steel & 270 & 270 & 630 & 435 & 590 \\
\hline $\begin{array}{l}\text { Through hardened alloy } \\
\text { steel }\end{array}$ & 270 & 270 & 670 & 540 & 1190 \\
\hline $\begin{array}{c}\text { Surface hardened alloy } \\
\text { steel }\end{array}$ & 585 & 240 & 1160 & 680 & 1580 \\
\hline Carburised steel & 700 & 315 & 1500 & 920 & 2300 \\
\hline Nitrided steel & 750 & 315 & 1250 & 760 & 1250 \\
\hline $\begin{array}{l}\text { Through hardened } \\
\text { carbon steel }\end{array}$ & 185 & 185 & 500 & 430 & 635 \\
\hline
\end{tabular}

Table 6. Final weights of attributes of second numerical example

\begin{tabular}{cccccc}
\hline Index & $\begin{array}{c}\text { Surface } \\
\text { hardness }\end{array}$ & $\begin{array}{c}\text { Core } \\
\text { hardness }\end{array}$ & $\begin{array}{c}\text { Surface } \\
\text { fatigue limit }\end{array}$ & $\begin{array}{c}\text { Bending } \\
\text { fatigue limit }\end{array}$ & $\begin{array}{c}\text { Ultimate } \\
\text { tensile strength }\end{array}$ \\
\hline Entropy value & 0.932 & 0.993 & 0.947 & 0.947 & 0.942 \\
\hline $\begin{array}{c}\text { Inherent } \\
\text { contrast } \\
\text { intensity }\end{array}$ & 0.068 & 0.007 & 0.053 & 0.053 & 0.058 \\
\hline Weight & $28.58 \%$ & $2.88 \%$ & $22.23 \%$ & $22.05 \%$ & $24.26 \%$ \\
\hline
\end{tabular}

The calculations of the weights of attributes are reported in Table 6 . It can be noticed that surface hardness is the most important attribute and then ultimate tensile strength while core hardness is the least important attribute. In this context, the weights of surface hardness, ultimate tensile strength and core hardness are $28.58 \%, 24.26 \%$ and $2.88 \%$, respectively. The rankings of the material alternatives are found in Table 7. Based on the six multi-criteria decision making algorithms, caburised steel is the most optimum material alternative followed by nitrided steel while cast iron is the least preferable alternative. The consensus final rankings of material alternatives are reported in Table 8 . Caburised is found as the best alternative with eight wins and zero losses while cast iron is the lowest ranking with zero wins and eight losses.

Table 7. Full rankings of material alternatives in the second numerical example

\begin{tabular}{ccccccc}
\hline Material alternative & TOPSIS & SAW & COPRAS & WPM & ARAS & CODAS \\
\hline Cast iron & 9 & 9 & 9 & 9 & 9 & 9 \\
\hline
\end{tabular}




\begin{tabular}{cllllll}
\hline Ductile iron & 8 & 8 & 7 & 7 & 8 & 7 \\
\hline S.G iron & 7 & 6 & 6 & 6 & 6 & 6 \\
\hline Cast alloy steel & 4 & 5 & 5 & 5 & 5 & 5 \\
\hline Through hardened alloy steel & 6 & 4 & 4 & 4 & 4 & 4 \\
\hline Surface hardened alloy steel & 3 & 3 & 3 & 3 & 3 & 3 \\
\hline Carburised steel & 1 & 1 & 1 & 1 & 1 & 1 \\
\hline Nitrided steel & 2 & 2 & 2 & 2 & 2 & 2 \\
\hline Through hardened carbon steel & 5 & 7 & 8 & 8 & 7 & 8 \\
\hline
\end{tabular}

Table 8. Final rankings of material alternatives in the second numerical example

\begin{tabular}{ccccc}
\hline Material alternative & Loss & Win & Difference & Rank \\
\hline Cast iron & 8 & 0 & -8 & 8 \\
\hline Ductile iron & 6 & 1 & -5 & 7 \\
\hline S.G iron & 5 & 3 & -2 & 6 \\
\hline Cast alloy steel & 4 & 4 & 0 & 5 \\
\hline $\begin{array}{c}\text { Through hardened alloy } \\
\text { steel }\end{array}$ & 3 & 5 & 2 & 4 \\
\hline $\begin{array}{c}\text { Surface hardened alloy } \\
\text { steel }\end{array}$ & 2 & 6 & 4 & 3 \\
\hline Carburised steel & 0 & 8 & 8 & 1 \\
\hline Nitrided steel & 1 & 7 & 6 & 2 \\
\hline $\begin{array}{c}\text { Through hardened carbon } \\
\text { steel }\end{array}$ & 6 & 1 & -5 & 7 \\
\hline
\end{tabular}

\subsection{Numerical Example (3)}

The third numerical example is designated for the selection of energy efficient materials, which is adopted from Bhowmik et al. [44]. The initial decision matrix is reported in Table 9. The third numerical example studies nine energy efficient materials which are: alkaline earth lead glass, silicon, cast magnesium, wrought magnesium, lanthanum commercial purity min $99 \%$, magnesium commercial purity, nickel iron chromium alloy HW grade and cerium commercial purity. The nine material options are assessed based on density $(\mathrm{C} 1)$, bulk modulus (C2), compressive strength (C3), thermal conductivity (C4), thermal expansion (C5), resistivity (C6), cost $(\mathrm{C} 7)$, energy production $(\mathrm{C} 8)$ and $\mathrm{CO}_{2}$ emissions (C9). In this regard, the nonbeneficial attributes encompass cost, energy production and $\mathrm{CO}_{2}$ emissions. On the contrary, the beneficial attributes are density, bulk modulus, compressive strength, thermal conductivity, thermal expansion and resistivity.

Table 9. Original decision matrix of third numerical example adopted from Bhowmik et al. [44]

\begin{tabular}{cccccccccc}
\hline $\begin{array}{c}\text { Material } \\
\text { alternative }\end{array}$ & C1 & C2 & C3 & C4 & C5 & C6 & C7 & C8 & C9 \\
\hline $\begin{array}{c}\text { Alkaline earth } \\
\text { lead glass }\end{array}$ & 0.113 & 4.83 & 36.5 & 0.47 & 5.27 & 1.22 & 74.7 & 2578 & 1.28 \\
\hline Silicon & 0.082 & 13.7 & 46.4 & 86.6 & 1.11 & 1.1 & 164 & 6164 & 3.07 \\
\hline Cast magnesium & 0.063 & 4.78 & 10.1 & 29.4 & 13.6 & 5.35 & 104 & 4.99 & 29 \\
\hline $\begin{array}{c}\text { Wrought } \\
\text { magnesium }\end{array}$ & 0.062 & 5.07 & 12.3 & 28.8 & 13.6 & 4.15 & 119 & 5.51 & 32 \\
\hline $\begin{array}{c}\text { Cast nickel iron } \\
\text { alloy }\end{array}$ & 0.29 & 18.8 & 31.9 & 6.35 & 6.38 & 108 & 112 & 1.37 & 7.98 \\
\hline $\begin{array}{c}\text { Lanthanum } \\
\text { commercial purity } \\
\text { min 99\% }\end{array}$ & 0.22 & 3.77 & 15.9 & 7.51 & 2.5 & 56 & 261 & 3.54 & 20.6 \\
\hline $\begin{array}{c}\text { Magnesium } \\
\text { commercial purity }\end{array}$ & 0.062 & 4.78 & 9.42 & 86.6 & 14.1 & 4.2 & 104 & 3.96 & 32.8 \\
\hline
\end{tabular}




\begin{tabular}{cccccccccc}
\hline $\begin{array}{c}\text { Nickel iron } \\
\text { chromium alloy } \\
\text { HW grade }\end{array}$ & 0.29 & 18.8 & 45.6 & 6.35 & 6.38 & 108 & 373 & 1.18 & 6.84 \\
\hline $\begin{array}{c}\text { Cerium } \\
\text { commercial purity }\end{array}$ & 0.238 & 2.32 & 13 & 5.77 & 3.33 & 75 & 673 & 6.57 & 38.2 \\
\hline
\end{tabular}

The entropy values and weights of attributes are recorded in Table 10. It is derived that energy production is the most important criterion followed by resistivity and then thermal conductivity. In this context, the weighing values of energy productivity, resistivity and thermal conductivity are $37.06 \%$, $15.62 \%$ and $13.96 \%$, respectively. Table 11 shows the rankings of the materials based on TOPSIS, SAW, COPRAS, WPM, ARAS and CODAS. Cast nickel iron alloy is found as the best material option based on TOPSIS and COPRAS. Nickel iron chromium alloy HW grade is selected as the best material based on SAW, WPM and ARAS. CODAS yielded cerium commercial purity as the optimum material alternative. Alkaline earth lead glass is the least preferable material option according to SAW, COPRAS, WPM and ARAS. Silicon is the worst material option according to TOPSIS and CODAS.
The final ranking outcome based on COPELAND algorithm is recorded in Table 12. Nickel iron chromium alloy HW grade attained the highest ranking with zero losses and eight wins. In addition, Alkaline earth lead glass has the lowest ranking with eight losses and zero wins.

Table 10. Final weights of attributes of third numerical example

\begin{tabular}{cccccccccc}
\hline Index & C1 & C2 & C3 & C4 & C5 & C6 & C7 & C8 & C9 \\
\hline Entropy value & 0.917 & 0.887 & 0.920 & 0.731 & 0.898 & 0.700 & 0.873 & 0.287 & 0.864 \\
\hline $\begin{array}{c}\text { Inherent contrast } \\
\text { intensity }\end{array}$ & 0.083 & 0.113 & 0.080 & 0.269 & 0.102 & 0.300 & 0.127 & 0.713 & 0.136 \\
\hline Weight & $4.32 \%$ & $5.88 \%$ & $4.15 \%$ & $13.96 \%$ & $5.29 \%$ & $15.62 \%$ & $6.63 \%$ & $37.06 \%$ & $7.09 \%$ \\
\hline Entropy value & 0.917 & 0.887 & 0.920 & 0.731 & 0.898 & 0.700 & 0.873 & 0.287 & 0.864 \\
\hline
\end{tabular}

Table 11. Full rankings of material alternatives in the third numerical example

\begin{tabular}{ccccccc}
\hline Material alternative & TOPSIS & SAW & COPRAS & WPM & ARAS & CODAS \\
\hline Alkaline earth lead glass & 8 & 9 & 9 & 9 & 9 & 7 \\
\hline Silicon & 9 & 5 & 8 & 8 & 4 & 9 \\
\hline Cast magnesium & 6 & 6 & 4 & 5 & 6 & 6 \\
\hline Wrought magnesium & 7 & 7 & 6 & 6 & 8 & 8 \\
\hline Cast nickel iron alloy & 1 & 2 & 1 & 2 & 2 & 3 \\
\hline Lanthanum commercial purity min 99\% & 4 & 4 & 5 & 3 & 5 & 5 \\
\hline Magnesium commercial purity & 3 & 3 & 3 & 4 & 3 & 4 \\
\hline Nickel iron chromium alloy HW grade & 2 & 1 & 2 & 1 & 1 & 2 \\
\hline Cerium commercial purity & 5 & 8 & 7 & 7 & 7 & 1 \\
\hline
\end{tabular}

Table 12. Final rankings of material alternatives in the third numerical example 


\begin{tabular}{ccccc}
\hline Alkaline earth lead glass & 8 & 0 & -8 & 8 \\
\hline Silicon & 7 & 1 & -6 & 7 \\
\hline Cast magnesium & 4 & 4 & 0 & 5 \\
\hline Wrought magnesium & 5 & 2 & -3 & 6 \\
\hline Cast nickel iron alloy & 1 & 7 & 6 & 2 \\
\hline Lanthanum commercial purity min $99 \%$ & 3 & 5 & 2 & 4 \\
\hline Magnesium commercial purity & 2 & 6 & 4 & 3 \\
\hline Nickel iron chromium alloy HW grade & 0 & 8 & 8 & 1 \\
\hline Cerium commercial purity & 5 & 2 & -3 & 6 \\
\hline
\end{tabular}

\subsection{Numerical example (4)}

The fourth numerical example is material selection problem of the tool holder used in hard milling. It is quote from Çalişkan et al. [45], and it accounts four material alternatives and six performance criteria (see Table 13). The material options are AISI 1020, AISI 1040, AISI 4140, AISI 6150, AISI 8620, maraging steel, AISI S5, tungsten carbide-cobalt and $\mathrm{Fe}-5 \mathrm{Cr}-\mathrm{Mo}-\mathrm{V}$. The four performance criteria involve Young's modulus (M1), compressive strength (M2), fracture toughness (M3), mechanical loss coefficient (M4), hardness (M5) and cost (M6). The beneficial attributes are Young's modulus, compressive strength and fracture toughness. The non-beneficial attributes are hardness and cost.

Table 13. Initial decision matrix of fourth numerical example borrowed from Çalişkan et al. [45]

\begin{tabular}{ccccccc}
\hline Material alternative & M1 & M2 & M3 & M4 & M5 & M6 \\
\hline AISI 1020 & 210 & 330 & 54.5 & 0.00111 & 150 & 0.67 \\
\hline AISI 1040 & 212 & 633 & 46 & 0.00117 & 355 & 0.7 \\
\hline AISI 4140 & 212 & 655 & 87.5 & 0.00052 & 305 & 0.86 \\
\hline AISI 6150 & 207 & 1575 & 38 & 0.00026 & 483 & 1.18 \\
\hline AISI 8620 & 207 & 360 & 111.5 & 0.00089 & 190 & 0.87 \\
\hline Maraging steel & 188 & 183 & 80 & 0.00071 & 532.5 & 6.97 \\
\hline AISI S5 & 210 & 1930 & 21 & 0.00002 & 771 & 7.99 \\
\hline Tungsten carbide-cobalt & 593 & 4405 & 14.1 & 0.00135 & 1250 & 79.6 \\
\hline Fe-5Cr-Mo-V & 213 & 1655 & 120 & 0.00113 & 448.5 & 1.73
\end{tabular}

1040 is in the first ranking with zero losses and

The criteria weights of the material selection of the tool holder are presented in Table 14. In it, cost is found as the most important criterion and then compressive strength while Young's modulus is the least important factor. It can be also observed that fracture toughness, mechanical loss coefficient and hardness have nearly the same relative importance. In this context, the relative importance weights of cost, compressive strength and Young's modulus are $56.79 \%, 16.59 \%$ and $3.76 \%$, respectively. Table 15 demonstrates the ranking results of the fourth numerical example solved using the six multicriteria decision making algorithms. AISI 1040 is the best material according to COPRAS, WPM and ARAS. AISI 1020, maraging steel and $\mathrm{Fe}-5 \mathrm{Cr}-\mathrm{Mo}-$ $\mathrm{V}$ are the best options based on the results of SAW, CODAS and TOPSIS, respectively. Table 16 illustrates the final ranking results based on COPELAND algorithm. It can be inferred that AISI seven wins. AISI 1020 is the second rank with one loss and seven wins. It is also found that maraging steel is in the lowest ranking with seven losses and zero wins.

Table 14. Final weights of attributes of fourth numerical example

$\begin{array}{lllllll}\text { Index } & \text { M1 } & \text { M2 } & \text { M3 } & \text { M4 } & \text { M5 } & \text { M6 }\end{array}$




\begin{tabular}{ccccccc}
\hline Entropy value & 0.959 & 0.820 & 0.922 & 0.913 & 0.916 & 0.384 \\
\hline Inherent contrast intensity & 0.041 & 0.180 & 0.078 & 0.087 & 0.084 & 0.616 \\
\hline Weight & $3.76 \%$ & $16.59 \%$ & $7.14 \%$ & $8.00 \%$ & $7.72 \%$ & $56.79 \%$ \\
\hline
\end{tabular}

Table 15. Full rankings of material alternatives in the fourth numerical example

\begin{tabular}{ccccccc}
\hline Material alternative & TOPSIS & SAW & COPRAS & WPM & ARAS & CODAS \\
\hline AISI 1020 & 7 & 1 & 2 & 2 & 2 & 2 \\
\hline AISI 1040 & 4 & 2 & 1 & 1 & 1 & 4 \\
\hline AISI 4140 & 5 & 4 & 4 & 3 & 4 & 5 \\
\hline AISI 6150 & 2 & 5 & 6 & 5 & 6 & 7 \\
\hline AISI 8620 & 6 & 3 & 3 & 4 & 3 & 3 \\
\hline Maraging steel & 8 & 8 & 9 & 7 & 9 & 1 \\
\hline AISI S5 & 3 & 9 & 8 & 8 & 8 & 9 \\
\hline Tungsten carbide-cobalt & 9 & 7 & 5 & 9 & 5 & 6 \\
\hline Fe-5Cr-Mo-V & 1 & 6 & 7 & 6 & 7 & 8 \\
\hline
\end{tabular}

Table 16. Final rankings of material alternatives in the fourth numerical example

\begin{tabular}{ccccc}
\hline Material alternative & Loss & Win & Difference & Rank \\
\hline AISI 1020 & 1 & 7 & 6 & 2 \\
\hline AISI 1040 & 0 & 8 & 8 & 1 \\
\hline AISI 4140 & 3 & 5 & 2 & 4 \\
\hline AISI 6150 & 5 & 2 & -3 & 6 \\
\hline AISI 8620 & 2 & 6 & 4 & 3 \\
\hline Maraging steel & 7 & 0 & -7 & 8 \\
\hline AISI S5 & 6 & 2 & -4 & 7 \\
\hline Tungsten carbide-cobalt & 4 & 1 & -3 & 5 \\
\hline Fe-5Cr-Mo-V & 5 & 2 & -3 & 6
\end{tabular}

\subsection{Numerical Example (5)}

This numerical example is adopted from Manshadi et al. [46] and it deals with the selection process of materials in mechanical components. Seven material options were examined, namely Al 2024-T6, Al 5052-O, SS 301-FH, SS 310-3AH, Ti-6Al-4V, Inconel 718 and $70 \mathrm{Cu}-30 \mathrm{Zn}$. This numerical example includes seven performance attributes which are toughness index (S1), yield strength (S2), Young's modulus (S3), density (S4), thermal expansion (S5), thermal conductivity (S6) and specific heat (S7) (see Table 17). The benefit attributes encompass yield strength and Young's

Table 17. Initial decision matrix of fifth numerical example extracted from Manshadi et al. [46]

\begin{tabular}{cccccccc}
\hline $\begin{array}{c}\text { Material } \\
\text { alternative }\end{array}$ & S1 & S2 & S3 & S4 & S5 & S6 & S7 \\
\hline A1 2024-T6 & 75.5 & 420 & 74.2 & 2.8 & 21.4 & 0.37 & 0.16 \\
\hline Al 5052-O & 95 & 91 & 70 & 2.68 & 22.1 & 0.33 & 0.16 \\
\hline SS 301-FH & 770 & 1365 & 189 & 7.9 & 16.9 & 0.04 & 0.08 \\
\hline SS 310-3AH & 187 & 1120 & 210 & 7.9 & 14.4 & 0.03 & 0.08 \\
\hline Ti-6Al-4V & 179 & 875 & 112 & 4.43 & 9.4 & 0.016 & 0.09 \\
\hline Inconel 718 & 239 & 1190 & 217 & 8.51 & 11.5 & 0.31 & 0.07 \\
\hline 70Cu-30Zn & 273 & 200 & 112 & 8.53 & 19.9 & 0.29 & 0.06 \\
\hline
\end{tabular}


Table 18. Final weights of attributes of fifth numerical example

\begin{tabular}{cccccccc}
\hline Index & S1 & S2 & S3 & S4 & S5 & S6 & S7 \\
\hline Entropy value & 0.855 & 0.879 & 0.954 & 0.953 & 0.979 & 0.819 & 0.964 \\
\hline Inherent contrast intensity & 0.145 & 0.121 & 0.046 & 0.047 & 0.021 & 0.181 & 0.036 \\
\hline Weight & $24.29 \%$ & $20.28 \%$ & $7.62 \%$ & $7.91 \%$ & $3.47 \%$ & $30.34 \%$ & $6.10 \%$
\end{tabular}

WPM. Furthermore, Ti-6Al-4V and $70 \mathrm{Cu}-30 \mathrm{Zn}$

Table 19 reports the rankings results of material options in the fifth case study. Al 5052-O is found as the least preferable material alternative based on the six multi-criteria decision making algorithms. SS 301-FH is selected as the best material option with regards to TOPSIS, SAW, COPRAS and are the most optimum materials with respect to ARAS and CODAS, respectively. The ranking results of COPELAND algorithm are shown in Table 20. SS 301-FH accomplished the first ranking with zero losses and six wins. Al 2024-T6 obtained the lowest ranking with five losses and one win.

Table 19. Initial decision matrix of fifth numerical example extracted from Manshadi et al. [36]

\begin{tabular}{ccccccc}
\hline Material alternative & TOPSIS & SAW & COPRAS & WPM & ARAS & CODAS \\
\hline Al 2024-T6 & 6 & 5 & 6 & 6 & 6 & 3 \\
\hline Al 5052-O & 7 & 7 & 7 & 7 & 7 & 7 \\
\hline SS 301-FH & 1 & 1 & 1 & 1 & 2 & 5 \\
\hline SS 310-3AH & 2 & 3 & 3 & 3 & 3 & 6 \\
\hline Ti-6Al-4V & 3 & 2 & 2 & 2 & 1 & 2 \\
\hline Inconel 718 & 4 & 4 & 4 & 4 & 4 & 4 \\
\hline $70 \mathrm{Cu}-30 \mathrm{Zn}$ & 5 & 6 & 5 & 5 & 5 & 1 \\
\hline
\end{tabular}

Table 20. Final rankings of material alternatives in the fifth numerical example

\begin{tabular}{ccccc}
\hline Material alternative & Loss & Win & Difference & Rank \\
\hline Al 2024-T6 & 5 & 1 & -4 & 7 \\
\hline Al 5052-O & 6 & 0 & -6 & 6 \\
\hline SS 301-FH & 0 & 6 & 6 & 1 \\
\hline SS 310-3AH & 2 & 4 & 2 & 3 \\
\hline Ti-6Al-4V & 1 & 5 & 4 & 2 \\
\hline Inconel 718 & 3 & 3 & 0 & 4 \\
\hline 70Cu-30Zn & 4 & 2 & -2 & 5 \\
\hline
\end{tabular}

\subsection{Spearman's Rank Correlation Analysis}

Table 21 shows the Spearman's rank correlation coefficient between the six deployed multi-criteria decision making algorithms. It should be noted that the values of Spearman's rank correlation coefficient are the average of the calculated Spearman's rank correlation coefficient from the five numerical examples. In this context, a Spearman's rank correlation matrix is constructed for each numerical example, and the values recorded in Table 21 are based on averaging Spearman's rank correlation coefficients of the five numerical examples. For instance, Spearman's rack correlation coefficient between CODAS and SAW is $18.95 \%$. This value is based on taking the average of Spearman's rack correlation coefficient between these two MCDM algorithms of the five numerical examples. Each entry of this matrix depicts the correlation between one MCDM algorithm and another one. The entries on the diagonal are equal to $100 \%$ since each MCDM algorithm is compared against itself. The highest correlation lies between the pair (COPRAS, WPM) followed by the pair (COPRAS, ARAS). In addition, the lowest agreement exists between the pairs (TOPSIS, CODAS) and (ARAS, CODAS). In this regard, the Spearman's rank correlation coefficient between the pairs (COPRAS, WPM), (COPRAS, ARAS), (TOPSIS, CODAS) and (ARAS, CODAS) are $92.67 \%, 92.62 \%, 18.95 \%$ and $21.62 \%$, respectively. The average Spearman's rank correlation coefficient of TOPSIS, SAW, COPRAS, WPM, ARAS and CODAS are $21.06 \%, 58.17 \%, 59.54 \%, 58.08 \%$, $57.02 \%$ and $20.26 \%$, respectively. This exemplifies that COPRAS is the most dominant multi-criteria 
decision making algorithm with regards to the agreement of its ranking with other algorithms. Hence, COPRAS is the most reliable ranking algorithm and it can be used as a reference for optimizing material selection. It is also noticed that TOPSIS and CODAS obtained low average Spearman's rank correlation coefficients, which demonstrates its inefficiency of TOPSIS in material selection problems despite its wide use.

Table 21. Spearman's rank correlation matrix between the applied multi-criteria decision making algorithms

\begin{tabular}{ccccccc}
\hline & TOPSIS & SAW & COPRAS & WPM & ARAS & CODAS \\
\hline TOPSIS & $100 \%$ & $37.57 \%$ & $47.62 \%$ & $55.62 \%$ & $45.52 \%$ & $18.95 \%$ \\
\hline SAW & $37.57 \%$ & $100 \%$ & $88.29 \%$ & $86.95 \%$ & $84.24 \%$ & $31.38 \%$ \\
\hline COPRAS & $47.62 \%$ & $88.29 \%$ & $100 \%$ & $92.67 \%$ & $92.62 \%$ & $24.14 \%$ \\
\hline WPM & $55.62 \%$ & $86.95 \%$ & $92.67 \%$ & $100 \%$ & $86.62 \%$ & $24.14 \%$ \\
\hline ARAS & $45.52 \%$ & $84.24 \%$ & $92.62 \%$ & $86.62 \%$ & $100 \%$ & $21.62 \%$ \\
\hline CODAS & $18.95 \%$ & $31.38 \%$ & $24.14 \%$ & $24.14 \%$ & $21.62 \%$ & $100 \%$
\end{tabular}

\section{Analysis and Discussion}

In the first example, the developed model selected tinted glass-double glazed as the best material. However, TOPSIS, SAW, WPM and CODAS failed to obtain the best material. COPRAS and ARAS are the only MCDM algorithms that were able to find the best material alternative. The second study showed a noticeable agreement in the rankings of material alternatives between the integrated model and the six MCDM algorithms, whereas all of them chose carburised steel as the optimum material alternative. In the third case study, nickel iron chromium alloy HW grade was found to be the best material option. SAW, WPM and ARAS also selected chromium alloy HW grade as the best material option. On the other hand, TOPSIS, COPRAS and CODAS were not able to identify the best material option. With regards to the fourth numerical example, AISI 1040 was defined as the best material capitalizing on the developed model. In addition, COPRAS, WPM and ARAS obtained the same results. On the contrary, TOPSIS, SAW and CODAS failed to find the best material option. With respect to the fifth numerical example, it was derived that SS 301-FH as the best option based on the developed integrated model. Furthermore, TOPSIS, SAW, COPRAS and WPM also identified SS 301-FH as the best option. On the other hand, ARAS and CODAS did not succeed in solving the material selection problem. In the light of foregoing, it can be interpreted that CODAS succeeded in solving only one numerical example.
Also, it is observed that TOPSIS and SAW were able to solve only two and three numerical examples successfully, respectively. Thus, CODAS and TOPSIS are not recommended to be exploited in solving similar material selection problems. It is also interpreted that COPRAS, ARAS and WPM managed to solve four numerical examples successfully. Another observation can be stated is that there are explicit perturbations in the rankings of MCDM algorithms in the first, third, fourth and fifth numerical examples. In the first one, clear glass was the best by TOPSIS and CODAS while tinted glass-double glazed was the best according to COPRAS and ARAS. Tinted glass-single glazed and glass plus $3 \mathrm{M}$ film were selected by WPM and SAW, respectively. In the third example, cast nickel iron alloy was considered ass the best option based on TOPSIS and COPRAS. Cerium commercial purity was regarded as the best option according to CODAS. Nickel iron chromium alloy HW grade was defined as the best option stepping on SAW, WPM and ARAS. At the level of fourth case study, AISI 1020, maraging steel, and $\mathrm{Fe}-5 \mathrm{Cr}-\mathrm{Mo}-\mathrm{V}$ were the most sustainable options according to SAW, CODAS and TOPSIS, respectively. AISI 1040 achieved the highest ranking according to COPRAS, WPM and ARAS. In the fifth case study, SS 301-FH obtained the highest ranking according to TOPSIS, SAW, COPRAS and WPM. Ti-6Al-4V and $70 \mathrm{Cu}-30 \mathrm{Zn}$ were found to be the best options based on ARAS and CODAS, respectively. In the light of above, it can be deduced that no single MCDM algorithm can be used to solve all material selection problems, which exemplifies the need for 
integrated decision support system that can account for the presence of several material alternatives and wide conflicting design attributes.

Another study is carried out to test the agreement between the utilized MCDM algorithms based on Spearman's rank correlation coefficients of the five numerical examples. Results showed low consensus between the rankings obtained from TOPSIS and CODAS and the remainder of the MCDM algorithms which illustrates their incapability to deal with such material selection problems. It is also found that COPRAS, WPM and ARAS managed to obtain similar ranking of material alternatives. In this context, COPRAS was found to yield the highest level of consensus with other MCDM algorithms with an average Spearman's rank correlation coefficient of $59.54 \%$. Thus, it is advised to be used over other individual MCDM algorithms in material selection problems.

\section{Conclusion}

Material selection is an exhaustive and challenging process due to the existence of various types of materials and complex relationships among them. In addition, they imply explicit implications on the company's reputation and productivity. Hence, this research proposes an integrated multi-criteria decision making platform to aid decision-makers in the reliable and sustainable optimization of materials in several disciplines. In the developed model, Shannon entropy is deployed for the sake of objective assessment of the relative importance of each performance criterion. The developed model exploits the use of six different types of MCDM algorithms in an attempt to create trustworthy selection of material alternatives. The used MCDM algorithms are TOPSIS, SAW, COPRAS, WPM, ARAS and CODAS. COPELAND algorithm is then applied to hybridize the ranking results of the MCDM algorithms and append the best material alternative. Average Spearman's rank correlation coefficient is employed to select the best MCDM algorithm stepping on measuring the similarities between the obtained ranks of the MCDM algorithms.

In the light of the obtained results of the five numerical examples, it can be observed no single MCDM algorithm managed to solve all the material selection problems successfully, whereas they proved to be case dependent. This necessitates the creation of an integrated decision support system to be able to deal with material selection problems. In the selection of construction materials, tinted glassdouble glazed is chosen as the best material option. However, TOPSIS, SAW, WPM and CODAS failed in this problem selecting other materials like clear glass, glass plus 3M film, and tinted glass-single glazed as the most sustainable materials. In the gear material selection example, a significant agreement is experienced between the developed model and the remainder of the MCDM algorithms since all of them chose carburised steel as the best material option. With regards to the selection of energy efficient materials, nickel iron chromium alloy HW grade was defined as the material option while TOPSIS, COPRAS and CODAS selected cast nickel iron alloy and cerium commercial purity. With respect to the material selection of tool holder in hard milling, the developed model yielded AISI 1040 as the most optimum material while TOPSIS, SAW and CODAS defined $\mathrm{Fe}-5 \mathrm{Cr}-\mathrm{Mo}-\mathrm{V}$, maraging steel and AISI 1020 as the most optimum materials. In the selection of mechanical components' materials, SS 301-FH was determined to be the best option. However, ARAS and CODAS failed in dealing with this problem obtaining $\mathrm{Ti}-$ $6 \mathrm{Al}-4 \mathrm{~V}$ and $70 \mathrm{Cu}-30 \mathrm{Zn}$ as the best options, respectively.

It can be also deduced that significant deviations are experienced in the rankings of MCDM algorithms such as the first, third, fourth and fifth numerical examples. In the first case study, clear glass was selected as the best alternative by TOPSIS and CODAS and at the same time it was regarded as the least alternative by the remainder MCDM algorithms. In the third case study, cast nickel iron alloy was the best option by TOPSIS and COPRAS. In addition, nickel iron chromium alloy HW grade was found as the best option based on SAW, WPM and ARAS while CODAS determined cerium commercial purity as the best alternative. At the level of fourth case study, AISI 1020 was determined as the best option by SAW and one of the least options by TOPSIS. CODAS chose maraging steel and it was regarded as one of the least material options by other MCDM algorithms. $\mathrm{Fe}-5 \mathrm{Cr}-\mathrm{Mo}-\mathrm{V}$ accomplished the best ranking by TOPSIS while it obtained low ranking by other MCDM algorithms. With respect to the fifth case study, $70 \mathrm{Cu}-30 \mathrm{Zn}$ was considered as the best option by CODAS while it achieved low rankings by other MCDM algorithms. This analysis of case studies substantiates the use of COPEALND algorithm to find the best material alternative. It was also inferred that the rankings of material alternatives are greatly identical to each other in the second numerical example.

With regards to Spearman's rank correlation analysis, it was also concluded that the top-ranked correlation was between WPM and COPRAS while the correlation between CODAS and ARAS 
exhibited the lowest rank. Results also showed that COPRAS is the best MCDM algorithm which can be used as a benchmark for material selection while CODAS and TOPSIS are inefficient in solving material selection problems. The main limitation of the developed model is its long computational time elicited from the need to implement six types of MCDM algorithms.

\section{References:}

[1] Jahan, A., Ismail, M. Y., Shuib, S., Norfazidah, D., \& Edwards, K. L. (2011). An aggregation technique for optimal decisionmaking in materials selection. Materials and Design, 32(10), 4918-4924.

[2] Ljungberg, L. Y. (2007). Materials selection and design for development of sustainable products. Materials and Design, 28(2), 466479.

[3] Su, L., He, H., \& Lu, H. (2019). Multicriteria decision making method with interval neutrosophic setting based on minimum and maximum operators. International Journal of Circuits, Systems and Signal Processing, 13, 177-182.

[4] Singh, A. K., Avikal, S., Sharma, A., \& Verma, R. P. (2021). Selection of suitable metal matrix composite for design application using MCDM approach. Materials Today: Proceedings, 1-5.

[5] Chatterjee, P., Mandal, N., Dhar, S., Chatterjee, S., \& Chakraborty, S. (2019). A novel decision-making approach for light weight environment friendly material selection. Materials Today: Proceedings, 22, 1460-1469.

[6] Dhanaraj, P. S., \& Rathinasuriyan, C. (2021). Selection of intense energy welding process for high strength aluminum alloy using AHP. Materials Today: Proceedings, 1-6.

[7] Reddy, L. S., Reddy, A. S., \& Reddy, S. S. P. (2019). A Quantitative Approach to Prioritize Sustainable Concrete. Civil Engineering Journal, 5(12), 2579-2586.

[8] Demir, A. (2020). A Knowledge-Based System for Fine Aggregate Material Problem Selection in Concrete Production. Hittite Journal of Science \& Engineering, 7(2), 99108.

[9] Zoghi, M., Rostami, G., Khoshand, A., \& Motalleb, F. (2021). Material selection in design for deconstruction using Kano model, fuzzyAHP and TOPSIS methodology. Waste Management and Research, 1-10.

[10] Patnaik, P. K., Swain, P. T. R., Mishra, S. K., Purohit, A., \& Biswas, S. (2020). Composite material selection for structural applications based on AHP-MOORA approach. Materials Today: Proceedings, 33, 5659-5663.

[11] Kiani, B., Liang, R. Y., \& Gross, J. (2018). Material selection for repair of structural concrete using VIKOR method. Case Studies in Construction Materials, 8, 489-497.

[12] Falqi, I. I., Ahmed, M., \& Mallick, J. (2019). Siliceous concrete materials management for sustainability using fuzzyTOPSIS approach. Applied Sciences, 9(17), 115.

[13] Rashid, K., Farooq, S., Mahmood, A., Iftikhar, S., \& Ahmad, A. (2020). Moving towards resource conservation by automated prioritization of concrete mix design. Construction and Building Materials, 236, 113.

[14] Marzouk, M. and Mohammed Abdelkader, E. (2019). "On the use of multi-criteria decision making methods for minimizing environmental emissions in construction projects". Decision Science Letters, 8(4), 373-392.

[15] Donyaii, A., Sarraf, A., \& Ahmadi, H. (2020). Using composite ranking to select the most appropriate Multi- Criteria DecisionMaking ( MCDM ) method in the optimal operation of the Dam reservoir. Journal of Hydraulic Structures, 6(2), 1-22.

[16] Lee, H. C., \& Chang, C. Ter. (2018). Comparative analysis of MCDM methods for ranking renewable energy sources in Taiwan. Renewable and Sustainable Energy Reviews, 92, 883-896.

[17] Sheikh, V., \& Izanloo, R. (2021). Assessment of low impact development stormwater management alternatives in the city of Bojnord, Iran. Urban Water Journal, 18(6), 449-464.

[18] Meshref, H. (2020). Predicting loan approval of bank direct marketing data using ensemble machine learning algorithms. International Journal of Circuits, Systems and Signal Processing, 14, 914-922.

[19] Eghbali-Zarch, M., Tavakkoli-Moghaddam, R., Dehghan-Sanej, K., \& Kaboli, A. (2021). Prioritizing the effective strategies for construction and demolition waste management using fuzzy IDOCRIW and WASPAS methods. Engineering, Construction and Architectural Management, 1-30.

[20] Mostafaeipour, A., \& Sadeghi Sedeh, A. (2019). Investigation of solar energy utilization for production of hydrogen and sustainable chemical fertilizer: A case study. International 
Journal of Energy Research, 43(14), 83148336.

[21] Bid, S., \& Siddique, G. (2019). Human risk assessment of Panchet Dam in India using TOPSIS and WASPAS Multi-Criteria DecisionMaking (MCDM) methods. Heliyon, 5(6), 1-13.

[22] Marzouk, M. and Mohammed Abdelkader, E. (2017). "Minimizing Construction Emissions using Building Information Modeling and Decision-Making Techniques". International Journal of 3-D Information Modeling, 6(2), 1435.

[23] Şahin, M. (2021). A comprehensive analysis of weighting and multicriteria methods in the context of sustainable energy. International Journal of Environmental Science and Technology, 18, 1591-1616.

[24] Sayadinia, S., \& Beheshtinia, M. A. (2020). Proposing a new hybrid multi-criteria decisionmaking approach for road maintenance prioritization. International Journal of Quality and Reliability Management, 1-19.

[25] Nasiri, M., Moghaddam, H. K., \& Hamidi, M. (2021). Development of multi-criteria decision making methods for reduction of seawater intrusion in coastal aquifers using SEAWAT code. Journal of Contaminant Hydrology, 242, 1-13.

[26] Sayadinia, S., \& Beheshtinia, M. A. (2020). Proposing a new hybrid multi-criteria decisionmaking approach for road maintenance prioritization. International Journal of Quality and Reliability Management, 1-19.

[27] Hussain, A., Chun, J., \& Khan, M. (2020). A novel customer-centric Methodology for Optimal Service Selection (MOSS) in a cloud environment. Future Generation Computer Systems, 105, 562-580.

[28] Valmohammadi, C., Faezy Razi, F., \& Einy, F. (2021). Six Sigma Project Selection Using the Hybrid Approach FAHP-FTOPSIS and Grey Relational Analysis Model. IEEE Engineering Management Review, 8581, 1-21.

[29] Yazdani, M., Torkayesh, A. E., SantibanezGonzalez, E. D., \& Otaghsara, S. K. (2020). Evaluation of renewable energy resources using integrated Shannon Entropy-EDAS model. Sustainable Operations and Computers, 1, 3542.

[30] Ghosh, B., \& Mukhopadhyay, S. (2021). Erosion susceptibility mapping of subwatersheds for management prioritization using MCDM-based ensemble approach. Arabian Journal of Geosciences, 14(1), 1-18.
[31] Sotoudeh-Anvari, A., Sadjadi, S. J., Molana, S. M. H., \& Sadi-Nezhad, S. (2018). A new MCDM-based approach using BWM and SAW for optimal search model. Decision Science Letters, 7(4), 395-404.

[32] Firouzi, S., Allahyari, M. S., Isazadeh, M., Nikkhah, A., \& Van Haute, S. (2021). Hybrid multi-criteria decision-making approach to select appropriate biomass resources for biofuel production. Science of the Total Environment, $770,1-10$.

[33] Almutairi, K., Mostafaeipour, A., Jahanshahi, E., Jooyandeh, E., Himri, Y., Jahangiri, M., Issakhov, A., Chowdhury, S., Dehshiri, S. J. D., Dehshiri, S. S. H., \& Techato, K. (2021). Ranking locations for hydrogen production using hybrid wind-solar: A case study. Sustainability, 13(8), 1-25.

[34] Ali, T., Nahian, A. J., \& Ma, H. (2020). A hybrid multi-criteria decision-making approach to solve renewable energy technology selection problem for Rohingya refugees in Bangladesh. Journal of Cleaner Production, 273, 1-12.

[35] Badi, I. A., Abdulshahed, A. M., \& Shetwan, A. G. (2018). A case study of supplier selection for asteelmaking company in libya by using the combinative distance-based assessment (codas) model. Decision Making: Applications in Management and Engineering, 1(1), 1-12.

[36] Ijadi Maghsoodi, A., Ijadi Maghsoodi, A., Poursoltan, P., Antucheviciene, J., \& Turskis, Z. (2019). Dam construction material selection by implementing the integrated SWARA-CODAS approach with target-based attributes. Archives of Civil and Mechanical Engineering, 19(4), 1194-1210.

[37] Mathew, M., \& Sahu, S. (2018). Comparison of new multi-criteria decision making methods for material handling equipment selection. Management Science Letters, 8(3), 139-150.

[38] Ecer, F. (2021). A consolidated MCDM framework for performance assessment of battery electric vehicles based on ranking strategies. Renewable and Sustainable Energy Reviews, 143, 1-19.

[39] Torkzad, A., \& Beheshtinia, M. A. (2019). Evaluating and prioritizing hospital service quality. International Journal of Health Care Quality Assurance, 32(2), 332-346.

[40] Beheshtinia, M. A., \& Omidi, S. (2017). A hybrid MCDM approach for performance evaluation in the banking industry. Kybernetes, 46(8), 1386-1407. 
[41] Kiani, M., Bagheri, M., Ebrahimi, A., \& Alimohammadlou, M. (2019). A model for prioritizing outsourceable activities in universities through an integrated fuzzy-MCDM method. International Journal of Construction Management, 1-17.

[42] Marzouk, M. M. (2011). Automation in Construction ELECTRE III model for value engineering applications. Automation in Construction, 20(5), 596-600.

[43] Milani, A. S., Shanian, A., Madoliat, R., \& Nemes, J. A. (2005). The effect of normalization norms in multiple attribute decision making models: A case study in gear material selection. Structural and Multidisciplinary Optimization, 29(4), 312-318.

[44] Bhowmik, C., Gangwar, S., Bhowmik, S., \& Ray, A. (2018). Optimum Selection of Energy-Efficient Material: A MCDM-Based Distance Approach. In Soft Computing Applications, 59-79.

[45] Çalişkan, H., Kurşuncu, B., Kurbanoĝlu, C., \& Güven, şevki Y. (2013). Material selection for the tool holder working under hard milling conditions using different multi criteria decision making methods. Materials and Design, 45, 473-479.

[46] Manshadi, D. B., Mahmudi, H., Abedian, A., \& Mahmudi, R. (2007). A novel method for materials selection in mechanical design: Combination of non-linear normalization and a modified digital logic method. Materials and Design, 28(1), 8-15.

\section{Contribution of Individual Authors to the Creation of a Scientific Article (Ghostwriting Policy)}

Eslam Mohammed Abdelkader analyzed the findings and the results of the models and aided in writing the article. Abobakr Al-Sakkaf developed the methodology and concept and aided in writing the article. Ghasan Alfalah aided in developing the methodology and concept and writing the article.

Creative Commons Attribution License 4.0 (Attribution 4.0 International, CC BY 4.0)

This article is published under the terms of the Creative Commons Attribution License 4.0 https://creativecommons.org/licenses/by/4.0/deed.en US 